Published in final edited form as:

Invest New Drugs. 2012 October ; 30(5): . doi:10.1007/s10637-011-9742-1.

\title{
Phase I study of temsirolimus in combination with EKB-569 in patients with advanced solid tumors
}

\author{
Alan H. Bryce, \\ Mayo Clinic, 13400 E Shea Blvd, Scottsdale, AZ 85255, USA \\ Ravi Rao, \\ Mayo Clinic, Rochester, MN, USA \\ Cancer Center at St Agnes, Fresno, CA, USA \\ Jann Sarkaria, \\ Mayo Clinic, Rochester, MN, USA \\ Joel M. Reid, \\ Mayo Clinic, Rochester, MN, USA \\ Yingwei Qi, \\ Mayo Clinic, Rochester, MN, USA \\ Rui Qin, \\ Mayo Clinic, Rochester, MN, USA \\ C. David James, \\ University of California, San Francisco, San Francisco, CA, USA \\ Robert B. Jenkins, \\ Mayo Clinic, Rochester, MN, USA \\ Joseph Boni, \\ Pfizer Oncology, Collegeville, PA, USA \\ Charles Erlichman, and \\ Mayo Clinic, Rochester, MN, USA \\ Paul Haluska \\ Mayo Clinic, Rochester, MN, USA \\ Alan H. Bryce: bryce.alan@mayo.edu
}

\section{Summary}

Purpose-Activation of EGFR can stimulate proliferative and survival signaling through mTOR. Preclinical data demonstrates synergistic activity of combined EGFR and mTOR inhibition. We undertook a phase I trial of temsirolimus (T, an mTOR inhibitor) and EKB-569 (E, an EGFR inhibitor) to determine the safety and tolerability.

Methods-The primary aim was to determine the maximally tolerated dose (MTD) of this combination in adults with solid tumors. Following the dose-escalation phase, (Cohort A), two subsequent cohorts were used to assess any pharmacokinetic (PK) interaction between the agents.

(C) Springer Science+Business Media, LLC 2011

Correspondence to: Alan H. Bryce, bryce . alan@mayo . edu.

Authors' Disclosure of Potential Conflicts of Interests JB is a paid employee of Pfizer, Inc. 
Results-Forty eight patients were enrolled. The MTD of this combination was E, $35 \mathrm{mg}$ daily and T, $30 \mathrm{mg}$ on days 1-3 and 15-17 using a 28 -day cycle. The most common toxicities were nausea, diarrhea, fatigue, anorexia, stomatitis, rash, anemia, neutropenia, thrombocytopenia, and hypertriglyceridemia. Sixteen patients (36\%) had at least one grade 3 toxicity. The most frequent grade $3 / 4$ toxicities were diarrhea, dehydration, and nausea and vomiting (19\% each). No grade 5 events were seen. Four patients had a partial response and 15 had stable disease. Clinical benefit was seen across a range of tumor types and in all cohorts. PK analysis revealed no significant interaction between $\mathrm{E}$ and $\mathrm{T}$.

Conclusions-This combination of agents is associated with tolerable toxicities at doses that induced responses. PK studies revealed no interaction between the drugs. Further investigations of this targeting strategy may be attractive in renal cell carcinoma, non-small cell lung cancer, alveolar sarcoma, and carcinoid tumor.

\section{Keywords}

CCI-779; EKB-569; Temsirolimus; Phase I; Pharmacokinetics; Solid tumors

\section{Introduction}

The mammalian target of rapamycin, mTOR, is a serine/threonine protein kinase that regulates cell proliferation, protein synthesis, survival and transcription through integration of stimulation from mitogenic upstream pathways [1,2], and dysregulation of this pathway has been implicated as an important mediator of certain cancers [3]. In response to input from HER family of receptors, VEGF, insulin, insulin-like growth factors, and other mitogenic stimuli critical to cancer growth and survival, mTOR is activated downstream of PI3K/Akt [4]. The persistent activation of PI3K/Akt pathway has been repeatedly demonstrated in laboratory models of resistance to anti-EGFR therapy, suggesting that downstream blockage of mTOR, may be helpful is overcoming crosstalk signaling through additional mitogenic pathways [4-7]. Thus, inhibitors of the mTOR pathway are an attractive anticancer strategy.

Temsirolimus (CCI-779) is a rapamycin analog with a more favorable pharmacokinetic profile that has been developed for clinical use as an inhibitor of mTOR. Temsirolimus has been approved for use as first line, single agent therapy in advanced renal cell carcinoma. Phase II studies with temsirolimus in mantle cell lymphoma have reported overall response rate of 38-41\% and a median TTP of 6 months $[8,9]$. Two trials in glioblastoma multiforme have shown a TTP of 9-38 weeks but with some partial responses and disease stability noted $[10,11]$. On the basis of these trials, further trials of agents in combination with temsirolimus in recurrent GBM are ongoing. Positive results were also reported in heavily pretreated advanced breast cancer, with a partial response rate of $9.2 \%$, and further trials are ongoing [12-15]. In a phase I study with oral administration, the recommended phase 2 single agent dose of temsirolimus was $75 \mathrm{mg} /$ day administered daily for 5 days every 2 weeks [16].. In a phase I study of IV administration, the toxicities were tolerable and reversible acne, rash, and mucositis up to a maximum tested dose of $220 \mathrm{mg} / \mathrm{m}^{2} \mathrm{IV}$ once weekly [17].

EKB-569 is a small molecule tyrosine kinase inhibitor (TKI) that is an irreversible, orally available, and selective inhibitor of EGFR which also binds to the ErBb2 receptor at higher concentrations [10]. A significant advantage to EKB-569 over the currently approved TKIs is its ability to overcome acquired or primary resistance to these drugs mediated by the T790M mutation in EGFR [11]. To date, 3 Phase I studies involving EKB-569 have been reported. The first examined EKB-569 as a single agent in advanced solid tumors [12], 
while the second and third examined combination therapy in metastatic colorectal cancer with capecitabine or 5-FU, leucovorin, and irinotecan (FOLFIRI) [13, 14], respectively. As a single agent, an MTD of $75 \mathrm{mg}$ daily with a DLT of grade 3 diarrhea was established. In combination with capecitabine, the MTD was $50 \mathrm{mg}$ daily with DLTs of diarrhea and rash; while the combination with FOLFIRI produced a recommended dose of $25 \mathrm{mg}$ daily with DLTs of diarrhea, neutropenia, and asthenia.

Our rationale for combining agents that inhibit mTOR and EGFR is based on the hypothesis that blocking the activity of 2 important signaling proteins will lead to a synergistic clinical benefit. This hypothesis is supported by our preclinical data in which we demonstrated that combining the EKB-569 analog EKI 875 and rapamycin led to a synergistic cytotoxicity in glioma cell lines [15].

The goals of this study were to: (1) determine the maximally tolerated dose of concurrently administered temsirolimus and EKB-569 in patients with advanced solid tumors; (2) describe the toxicity of the treatment combination; (3) describe the response rate of the treatment combination (4) to establish the pharmacokinetics of the drugs in combination.

\section{Patients and methods}

\section{Patient selection}

Patients over 18 years of age with histologic proof of cancer that was unresectable were eligible for this study. Patients had to be able to provide informed consent, have an estimated life expectancy $\geq 12$ weeks, an ECOG performance status (PS) $\mathcal{2}$, and had to be willing to return to Mayo Clinic for follow-up. Adequate organ function was defined based on laboratory values obtained $\leq 4$ days prior to registration: (1) ANC $\geq 1500 / \mu \mathrm{L}$; (2) PLT $\geq 100,000 / \mu \mathrm{L}$; (3) total bilirubin supper limit of normal (ULN); (4) AST $3 \times$ ULN or AST $5 \times$ ULN if liver involvement; (5) creatinine $\unlhd .5 \times$ ULN; (6) fasting cholesterol $<350 \mathrm{mg}$ / $\mathrm{dL}$; (7) fasting triglycerides $<400 \mathrm{mg} / \mathrm{dL}$; (8) $\mathrm{Hgb} \geq 10 \mathrm{~g} / \mathrm{dL}$. Women of childbearing potential only were required to have a negative serum pregnancy test done $\leq 7$ days prior to registration.

Patients were excluded if they had used any of CYP3A4 inducing drugs $\leq 7$ days prior to registration, if there was known standard therapy for the patient's disease that was potentially curative or definitely capable of extending life expectancy, if they had any uncontrolled infection, or HIV positive patients on antiretroviral agents that undergo CYP3A4 metabolism. Further exclusion criteria included prior therapies with any agent targeting EGFR or mTOR, chemotherapy $\leqslant 4$ weeks prior to study entry, mitomycin C/

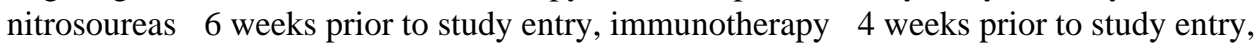
biologic therapy $\leq 4$ weeks prior to study entry, radiation therapy $\leq 4$ weeks prior to study entry, and radiation to $>30 \%$ of bone marrow, failure to fully recover from acute, reversible effects of prior chemotherapy regardless of interval since last treatment, New York Heart Association classification III or IV, CNS metastases or seizure disorder, other concurrent chemotherapy, immunotherapy, radiotherapy, or any ancillary therapy considered investigational, concurrent use of warfarin or oral contraceptives or any of the following: (1) pregnant women; (2) nursing women; (3) men or women of childbearing potential who are unwilling to employ adequate contraception.

\section{Trial design and treatment}

Patients were treated on a 28 day cycle. The initial dosing plan is outlined in Table 1 . In the original dose escalation cohort (Cohort A1), EKB-569 was given orally on a daily basis on days 1-28, and temsirolimus was given orally on days 1-7 and 15-21 with the dose escalations of both drugs as part of the schema. The intermittent oral dosing schedule for the 
temsirolimus was modeled on previous phase I data with a significant reduction of the starting dose [16].

As no tolerable dose was found with the original dosing scheme in cohort A1, the protocol was amended with a new dosing cohort designated as Cohort A2, in which EKB-569 was given orally daily on days 1-28 and temsirolimus was reduced and given orally on days 1-3 and 15-17. In this new dose escalation design, the dose of temsirolimus was fixed at $30 \mathrm{mg}$ and EKB-569 was started at $10 \mathrm{mg}$.

Dose escalation was performed in a standard cohort of $3+3$ design. Three patients were treated at a given dose level and observed for at least 4 weeks to assess toxicity before new patients are treated. Doses were not escalated in any individual patient.

All toxicities were graded according to the National Cancer Institute common toxicity criteria (version 3.0). Nonhematologic toxicity $\geq$ Grade 3 was considered dose limiting. Grade 4 neutropenia, Grade 4 anemia, platelets $<25,000$ and serum creatinine $\geq 2$ times baseline were also considered dose limiting. Any persistent or intolerable toxicity leading to dose delay or dose reduction was also considered dose limiting. The maximally tolerated dose (MTD) was defined as one dose level below the lowest dose that induces dose-limiting toxicity in at least one-third of patients (at least 2 of a maximum of 6 new patients).

After the MTD was reached, accrual continued in two additional cohorts designated B and C consisting of six patients each for correlative studies and to assess potential pharmacokinetic interactions. In Cohort B EKB-569 was administered on days 4-28 of cycle 1 and days 1-28 of each subsequent cycle. Temsirolimus was given on days 1-3 and 15-17 of all cycles. This dosing strategy was employed to evaluate temsirolimus and active metabolite sirolimus plasma levels before and after initial and steady-state levels of EKB-569. In Cohort C EKB-569 was given on days 1-28 of all cycles, while temsirolimus was given on days 7-9 and 19-21 of cycle 1 , then on days $1-3$ and $15-17$ of all subsequent cycles. This dosing strategy was employed to evaluate EKB-569 and active metabolite N-desmethy EKB-569 plasma levels before and after initial and steady-state levels of EKB-569 (Fig. 1).

\section{Pretreatment and patient follow-up evaluation}

A clinical evaluation including history, physical exam, complete blood count, chemistries, electrolytes, and CT scans were done at baseline and re-evaluated for response every 8 weeks. In addition to a baseline scan, confirmatory scans were to be obtained 4 weeks following initial documentation of objective response. A modified Response Evaluation Criteria in Solid Tumors (RECIST) criteria in which only 3 measurable lesions were included was used [18]. Patients were followed for a maximum of 3 months after they went off-treatment.

Descriptive statistics and frequency distributions were used to summarize the patient characteristics, toxicity patterns and response.

\section{Pharmacokinetic methods}

Separate blood samples were drawn for determinations of EKB-569 and temsirolimus. Whole blood samples $(3 \mathrm{ml})$ for determination of temsirolimus and sirolimus were collected into tubes containing sodium EDTA, transferred to polypropylene tubes, and stored frozen at $-70^{\circ} \mathrm{C}$ in an upright position until shipment to the analytical laboratory. Venous blood (5 $\mathrm{ml}$ ) for determination of EKB-569 and its des-methyl and N-oxidemetabolites were collected into EDTA-containing tubes. After gentle inversion (4-5 times), plasma was separated by centrifugation in a refrigerated centrifuge $\left(\sim 5^{\circ} \mathrm{C}\right)$ within 15 min after collection, transferred to a watertight plastic tube, and stored frozen at $-70^{\circ} \mathrm{C}$ in an upright 
position until shipment to the analytical laboratory. Specimens were analyzed using LC/MS methods developed by Wyeth-Ayerst, as previously described [12, 19, 20].

In Cohort A2, samples were collected before the daily dose on Days 1 (Pretreatment), 2, 3 and 4. In Cohort B, samples were collected before the daily dose, and $2 \mathrm{~h}, 6 \mathrm{~h}$ and $24 \mathrm{~h}$ after the daily dose on Day 1, 3, 15 and 17. In Cohort $C$, samples were collected before the daily dose, and $6 \mathrm{~h}$ and $24 \mathrm{~h}$ after the daily dose on Day 1, 6, 7 and 9.

\section{Results}

\section{Patient characteristics}

Forty-eight patients ( 13 in Cohort A1, 22 in Cohort A2, 7 from Cohort B, and 6 from Cohort C) were enrolled between October 25, 2004 and September 11, 2007. Of these, 2 patients in Cohort A1, and 1 patient in Cohort A2 were replaced for DLT evaluation due to withdrawal prior to completion of DLT evaluation period. One patient in Cohort B was replaced due to hospitalization and received no treatment. These 4 patients were excluded from study analysis leaving 44 evaluable patients. All patients are off treatment at the time of this analysis.

Baseline characteristics of the patients are summarized in Table 2. The median age was 58 years old (range 24-84), with 23 women and 21 men. Nearly all were Caucasian (41 patients, 93\%), with 2 African American and 1 Asian. The population was heavily pretreated, with all having had prior surgery. 35 (80\%) of patients had prior chemotherapy, and 17 (39\%) of patients prior radiation therapy.

Patients received a median of 2 cycles of therapy (range 1-32). At the time of last follow-up $38(86 \%)$ were alive and $34(77 \%)$ had progressive disease. The primary reason for coming off study was disease progression (34 patients, $77 \%$ ), while 5 patients (11\%) had adverse events, 3 patients refused further treatment, 1 died of his disease, and 1 patient with ongoing toxicity in whom the lowest dose level had been reached on Cohort A1.

\section{Dose escalation}

DLT was seen in two patients at dose level 1 Cohort A1. One patient had grade 3 oral cavity mucositis and rash/desquamation; and one patient had grade 3 diarrhea, dehydration and anorexia. Two patients at dose level -1 , experienced a DLT, with one patient having grade 2 oral cavity mucositis and one patient grade 3 diarrhea and oral cavity mucositis. At dose level -2 in Cohort A1, two patients developed intolerable toxicity with mucositis and neutropenia in one patient and grade 3 fatigue in another and the schedule was abandoned. In Cohort A2, DLT was seen in one patient at dose level 0 (grade 2 AST), one patient at dose level 3 (grade 3 stomatitis/oral cavity mucositis and pain), and two patients at dose level 4 (one patient had grade 2 oral cavity mucositis, weight loss, and taste and one patient had grade 2 hand/foot syndrome) (Table 3). Although the toxicities at dose level 4 only qualified as grade 2, they necessitated a dose delay, and thus qualified as DLTs. Therefore, the MTD dose was $35 \mathrm{mg} / \mathrm{d}$ of EKB569 and $30 \mathrm{mg} / \mathrm{d}$ of temsirolimus and patients in Cohorts B and C were enrolled at this dose (level 3 in Cohort A2).

\section{Toxicity}

The most common toxicities were nausea, diarrhea, fatigue, anorexia, stomatitis, rash, anemia, neutropenia, thrombocytopenia, and hypertriglyceridemia. Sixteen patients (36\%) had at least one grade 3 or 4 toxicity (Fig. 2a and b). The most frequent grade $3 / 4$ toxicities were diarrhea, dehydration, and nausea and vomiting (19\% each). 
No grade 5 events were seen in this study. Only 2 grade 4 events (both deemed possible related) were seen in 2 patients from Cohort $\mathrm{C}$ (one patient had hypokalemia; and one patient had neutropenia). Neither of these toxicities were seen in the MTD dose level in Cohort A2. In Cohort B, there was one grade 3 AST elevation and one grade 3 leukopenia and neutropenia.

\section{Efficacy}

Out of the 15 patients who had stable disease as their best response, one patient had stable disease for 5 cycles, one patient had stable disease for 2 cycles, and two patients had stable disease for 1 cycle in Cohort A1. Two patients had stable disease for 3 cycles and six patients had stable disease for 1 cycle in Cohort A2. In Cohort B one patient had stable disease for 8 cycles and one patient had stable disease for 5 cycles and in Cohort $\mathrm{C}$ one patient had stable disease for 1 cycle (Table 4).

Two patients in Cohort A1 had partial responses (PR). One patient with a metastatic carcinoid tumor had a PR for 21 cycles and another with renal cell carcinoma had a PR for 5 cycles. From Cohort $\mathrm{C}$ one patient with a non-small cell carcinoma of unknown primary had a PR for 5 cycles and another with alveolar soft part sarcoma had a PR for 3 cycles.

\section{Pharmacokinetics}

In Cohort A2 temsirolimus Day $2(0.95 \pm 0.45 \mathrm{ng} / \mathrm{ml})$ and Day $4(1.49 \pm 0.48 \mathrm{ng} / \mathrm{ml})$ trough concentrations were maintained as the EKB-569 dose was increased from 10-35 mg/day. Temsirolimus Day $2(2.49 \pm 1.75 \mathrm{ng} / \mathrm{ml})$ and Day $4(2.49 \pm 1.36 \mathrm{ng} / \mathrm{ml})$ trough concentrations increased approximately 2-fold when the EKB-569 dose was increased to $45 \mathrm{mg} /$ day. However, sirolimus trough concentrations did not appear to differ between dose levels as the EKB-569 dose was increased from 10-45 mg/day. The sirolimus Day 4 trough concentration remained unchanged $(20.9 \pm 19.8 \mathrm{ng} / \mathrm{ml}$ versus $23.0 \pm 19.1 \mathrm{ng} / \mathrm{ml})$ as the EKB-569 dose was increased from $10-45 \mathrm{mg} /$ day.

The accumulation of temsirolimus in Cohort $\mathrm{B}$ and EKB-569 in Cohort $\mathrm{C}$ are summarized in Table 5A and B, respectively. In Cohort B, when EKB-569 was added to temsirolimus on Day 15 , temsirolimus $\mathrm{AUC}_{(0-24 \mathrm{~h})}$ values increased by $66 \%$ when compared to day 1 while sirolimus $\mathrm{AUC}_{(0-24 \mathrm{~h})}$ values were similar on day 1 and day 15 . The day $17 /$ day $3 \mathrm{AUC}_{(0-24 \mathrm{~h})}$ ratios indicate that both temsirolimus and sirolimus $\mathrm{AUC}_{(0-24 \mathrm{~h})}$ values were higher after 3 days of temsirolimus and EKB-569 (day 17) compared to 3 days of temsirolimus alone (Day $3)$. Given the high variability between patients it is unclear the increased $\mathrm{AUC}_{(0-24 \mathrm{~h})}$ is due to an interaction between temsirolimus and EKB-569.

In Cohort $\mathrm{C}$, when temsirolimus was added to EKB-569 on Day 7, EKB-569 $\mathrm{AUC}_{(0-24 \mathrm{~h})}$ values increased by about $19 \%$ with little additional accumulation on Day $9 . \mathrm{AUC}_{(0-24 \mathrm{~h})}$ values of the N-desmethyl metabolite of EKB-569 were $40 \%$ higher on Day 7 and nearly 2fold higher on Day 9. However, the variability between patients was also high on Day 9. (Table 5B)

\section{Discussion}

The novel combination of temsirolimus and EKB-569 in this trial resulted in partial responses at the MTD. The initially designed dose escalation scheme proved to be poorly tolerated, necessitating a revised dosing strategy denoted Cohort A2. With the revised schema an MTD of EKB-569 at $35 \mathrm{mg}$ once daily and Temsirolimus at $30 \mathrm{mg}$ once daily on days $1-3$ and $15-17$ every 28 days was identified. 
The most frequent grade 3 and 4 toxicities were diarrhea, nausea, and vomiting, which is consistent with previous reports of Phase I studies with EKB-569. The stomatitis and rash in our study is more consistent with prior studies of temsirolimus. The grade 3 and 4 hematologic toxicities are greater than what has been seen with either agent alone.

As temsirolimus and EKB-569 are both substrates for CYP3A4, the poor tolerability of the initial drug regimen could be explained in part by inhibition of CYP3A4-catalyzed metabolism of both drugs. Thus a pharmacokinetic study was included to investigate the possibility of a drug interaction. Unsurprisingly, the small number of patients in each cohort and large interpatient variability in AUC values do not permit definitive assessment of a drug-drug interaction for temsirolimus and EKB-569. However, it is unlikely that temsirolimus inhibits the metabolism of EKB-569 at the doses administered in this trial, since administration of temsirolimus with EKB-569 did not reduce the AUC of N-desmethyl EKB-569 which is formed by CYP3A4-catalyzed metabolism of EKB-569. The effect of EKB-569 on temsirolimus metabolism is unclear since sirolimus is formed by carboxylesterase-catalyzed metabolism of temsirolimus rather than CYP3A4-catalyzed metabolism. Further evaluation would be needed with this combination to draw definitive conclusions, though it did not appear that there was a clear pharmacological interaction between the two agents. In light of this and the enhanced toxicity over what is seen with either agent alone, our results suggest that EKB-569 and temsirolimus enhance each others toxicity in an on target fashion rather than through pharmacokinetic interaction.

Our study suggests that further study combining mTOR and a TKI of the EGFR is an attractive strategy, but that the potential for overlapping toxicity also exists. As the synergy is potentially class specific, these data should be considered in future trials of agents simultaneously blocking EGFR and mTOR.

The partial responses seen in this study are consistent with what has been seen with each drug as a single agent. These responses were observed in carcinoid tumor, renal cell cancer, non-small cell cancer, and alveolar soft part sarcoma.

Clinical development of small molecule EGFR inhibitors with mTOR inhibitors are continuing with temsirolimus in combination with the irreversible pan-erbB receptor tyrosine kinase inhibitor, neratinib (NCT00838539), a more potent analog of EKB-569 [21, 22]. Additionally, investigations are ongoing with everolimus and the pan-erbB inhibitor, lapatinib (NCT00352443), a reversible pan-erbB receptor tyrosine kinase inhibitor [23, 24].

\section{Acknowledgments}

Supported CA69912, 5ULRR024150, and CA090628

\section{References}

1. Barbet NC, Schneider U, Helliwell SB, Stansfield I, Tuite MF, Hall MN. TOR controls translation initiation and early G1 progression in yeast. Mol Biol Cell. 1996; 7(1):25-42. [PubMed: 8741837]

2. Hay N, Sonenberg N. Upstream and downstream of mTOR. Genes Dev. 2004; 18(16):1926-1945. [PubMed: 15314020]

3. Beevers CS, Li F, Liu L, Huang S. Curcumin inhibits the mammalian target of rapamycin-mediated signaling pathways in cancer cells. Int J Cancer. 2006; 119(4):757-764. [PubMed: 16550606]

4. Engelman JA, Zejnullahu K, Mitsudomi T, Song Y, Hyland C, Park JO, Lindeman N, Gale CM, Zhao X, Christensen J, Kosaka T, Holmes AJ, Rogers AM, Cappuzzo F, Mok T, Lee C, Johnson BE, Cantley LC, Janne PA. MET amplification leads to gefitinib resistance in lung cancer by activating ERBB3 signaling. Science. 2007; 316(5827):1039-1043. [PubMed: 17463250] 
5. Engelman JA, Janne PA. Mechanisms of acquired resistance to epidermal growth factor receptor tyrosine kinase inhibitors in non-small cell lung cancer. Clin Cancer Res. 2008; 14(10):2895-2899. [PubMed: 18483355]

6. Ogino A, Kitao H, Hirano S, Uchida A, Ishiai M, Kozuki T, Takigawa N, Takata M, Kiura K, Tanimoto M. Emergence of epidermal growth factor receptor T790M mutation during chronic exposure to gefitinib in a non small cell lung cancer cell line. Cancer Res. 2007; 67(16):7807-7814. [PubMed: 17699786]

7. Yamasaki F, Johansen MJ, Zhang D, Krishnamurthy S, Felix E, Bartholomeusz C, Aguilar RJ, Kurisu K, Mills GB, Hortobagyi GN, Ueno NT. Acquired resistance to erlotinib in A-431 epidermoid cancer cells requires down-regulation of MMAC1/PTEN and up-regulation of phosphorylated Akt. Cancer Res. 2007; 67(12):5779-5788. [PubMed: 17575145]

8. Ansell SM, Inwards DJ, Rowland KM Jr, Flynn PJ, Morton RF, Moore DF Jr, Kaufmann SH, Ghobrial I, Kurtin PJ, Maurer M, Allmer C, Witzig TE. Low-dose, single-agent temsirolimus for relapsed mantle cell lymphoma: a phase 2 trial in the North Central Cancer Treatment Group. Cancer. 2008; 113(3):508-514. [PubMed: 18543327]

9. Witzig TE, Geyer SM, Ghobrial I, Inwards DJ, Fonseca R, Kurtin P, Ansell SM, Luyun R, Flynn PJ, Morton RF, Dakhil SR, Gross H, Kaufmann SH. Phase II trial of single-agent temsirolimus (CCI-779) for relapsed mantle cell lymphoma. J Clin Oncol. 2005; 23(23):5347-5356. [PubMed: 15983389]

10. Torrance CJ, Jackson PE, Montgomery E, Kinzler KW, Vogelstein B, Wissner A, Nunes M, Frost $\mathrm{P}$, Discafani CM. Combinatorial chemoprevention of intestinal neoplasia.[see comment]. Nat Med. 2000; 6(9):1024-1028. [PubMed: 10973323]

11. Carter TA, Wodicka LM, Shah NP, Velasco AM, Fabian MA, Treiber DK, Milanov ZV, Atteridge CE, Biggs WH 3rd, Edeen PT, Floyd M, Ford JM, Grotzfeld RM, Herrgard S, Insko DE, Mehta SA, Patel HK, Pao W, Sawyers CL, Varmus H, Zarrinkar PP, Lockhart DJ. Inhibition of drugresistant mutants of ABL, KIT, and EGF receptor kinases. Proc Natl Acad Sci U S A. 2005; 102(31):11011-11016. [PubMed: 16046538]

12. Erlichman C, Hidalgo M, Boni JP, Martins P, Quinn SE, Zacharchuk C, Amorusi P, Adjei AA, Rowinsky EK. Phase I study of EKB-569, an irreversible inhibitor of the epidermal growth factor receptor, in patients with advanced solid tumors.[see comment]. J Clin Oncol. 2006; 24(15):22522260. [PubMed: 16710023]

13. Laheru D, Croghan G, Bukowski R, Rudek M, Messersmith W, Erlichman C, Pelley R, Jimeno A, Donehower R, Boni J, Abbas R, Martins P, Zacharchuk C, Hidalgo M. A phase I study of EKB-569 in combination with capecitabine in patients with advanced colorectal cancer. Clin Cancer Res. 2008; 14(17):5602-5609. [PubMed: 18765554]

14. Folprecht G, Tabernero J, Kohne CH, Zacharchuk C, Paz-Ares L, Rojo F, Quinn S, Casado E, Salazar R, Abbas R, Lejeune C, Marimon I, Andreu J, Ubbelohde U, Cortes-Funes H, Baselga J. Phase I pharmacokinetic/pharmacodynamic study of EKB-569, an irreversible inhibitor of the epidermal growth factor receptor tyrosine kinase, in combination with irinotecan, 5-fluorouracil, and leucovorin (FOLFIRI) in first-line treatment of patients with metastatic colorectal cancer. Clin Cancer Res. 2008; 14(1):215-223. [PubMed: 18172273]

15. Rao RD, Mladek AC, Lamont JD, Goble JM, Erlichman C, James CD, Sarkaria JN. Disruption of parallel and converging signaling pathways contributes to the synergistic antitumor effects of simultaneous mTOR and EGFR inhibition in GBM cells. Neoplasia (New York). 2005; 7(10):921929.

16. Buckner JC, Forouzesh B, Erlichman C, Hidalgo M, Boni JP, Dukart G, Berkenblit A, Rowinsky EK. Phase I, pharmacokinetic study of temsirolimus administered orally to patients with advanced cancer. Invest New Drugs. 2010; 28(3):334-342. [PubMed: 19415181]

17. Raymond E, Alexandre J, Faivre S, Vera K, Materman E, Boni J, Leister C, Korth-Bradley J, Hanauske A, Armand JP. Safety and pharmacokinetics of escalated doses of weekly intravenous infusion of CCI-779, a novel mTOR inhibitor, in patients with cancer.[see comment]. J Clin Oncol. 2004; 22(12):2336-2347. [PubMed: 15136596]

18. Therasse P, Arbuck SG, Eisenhauer EA, Wanders J, Kaplan RS, Rubinstein L, Verweij J, Van Glabbeke M, van Oosterom AT, Christian MC, Gwyther SG. New guidelines to evaluate the response to treatment in solid tumors. European Organization for Research and Treatment of 
Cancer, National Cancer Institute of the United States, National Cancer Institute of Canada.[see comment]. J Natl Cancer Inst. 2000; 92(3):205-216. [PubMed: 10655437]

19. Amorusi, P. Pearl River (NY): 2001. EKB-569: validation of an LC/MS/MS bioanalytical method for the quantitation of EKB-569 in human plasma. Wyeth-Ayerst Research RPT-40374. WyethAyerst Research RPT-40374, vol Wyeth-Ayerst Research RPT-40374.

20. Punt CJ, Boni J, Bruntsch U, Peters M, Thielert C. Phase I and pharmacokinetic study of CCI-779, a novel cytostatic cell-cycle inhibitor, in combination with 5-fluorouracil and leucovorin in patients with advanced solid tumors. Ann Oncol. 2003; 14(6):931-937. [PubMed: 12796032]

21. Wong KK, Fracasso PM, Bukowski RM, Lynch TJ, Munster PN, Shapiro GI, Janne PA, Eder JP, Naughton MJ, Ellis MJ, Jones SF, Mekhail T, Zacharchuk C, Vermette J, Abbas R, Quinn S, Powell C, Burris HA. A phase I study with neratinib (HKI-272), an irreversible pan ErbB receptor tyrosine kinase inhibitor, in patients with solid tumors. Clin Cancer Res. 2009; 15(7):2552-2558. [PubMed: 19318484]

22. Tsou HR, Overbeek-Klumpers EG, Hallett WA, Reich MF, Floyd MB, Johnson BD, Michalak RS, Nilakantan R, Discafani C, Golas J, Rabindran SK, Shen R, Shi X, Wang YF, Upeslacis J, Wissner A. Optimization of 6,7-disubstituted-4-(arylamino)quinoline-3-carbonitriles as orally active, irreversible inhibitors of human epidermal growth factor receptor-2 kinase activity. J Med Chem. 2005; 48(4):1107-1131. [PubMed: 15715478]

23. Burris HA 3rd, Hurwitz HI, Dees EC, Dowlati A, Blackwell KL, O'Neil B, Marcom PK, Ellis MJ, Overmoyer B, Jones SF, Harris JL, Smith DA, Koch KM, Stead A, Mangum S, Spector NL. Phase I safety, pharmacokinetics, and clinical activity study of lapatinib (GW572016), a reversible dual inhibitor of epidermal growth factor receptor tyrosine kinases, in heavily pretreated patients with metastatic carcinomas. J Clin Oncol. 2005; 23(23):5305-5313. [PubMed: 15955900]

24. Wood ER, Truesdale AT, McDonald OB, Yuan D, Hassell A, Dickerson SH, Ellis B, Pennisi C, Horne E, Lackey K, Alligood KJ, Rusnak DW, Gilmer TM, Shewchuk L. A unique structure for epidermal growth factor receptor bound to GW572016 (Lapatinib): relationships among protein conformation, inhibitor off-rate, and receptor activity in tumor cells. Cancer Res. 2004; 64(18): 6652-6659. [PubMed: 15374980] 


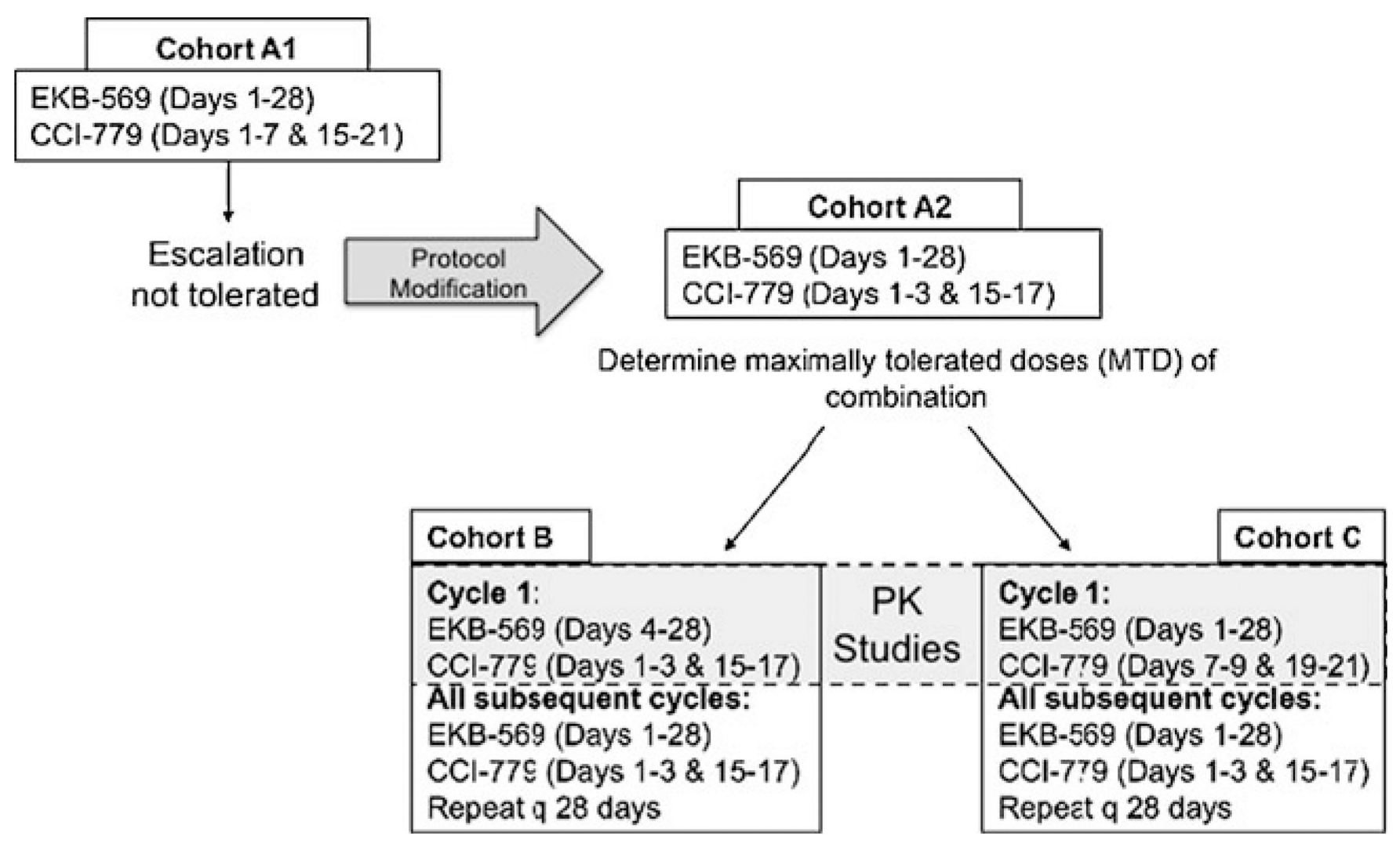

Fig. 1.

Treatment Schema- Cohort A1 represents the initial dose escalation schema, which was modified (Cohort A2). At the MTD, two additional cohorts of 6 patients were accrued with single drug run-in periods (Cohort B, temsirolimus run in; Cohort C, EKB-569 run in) 


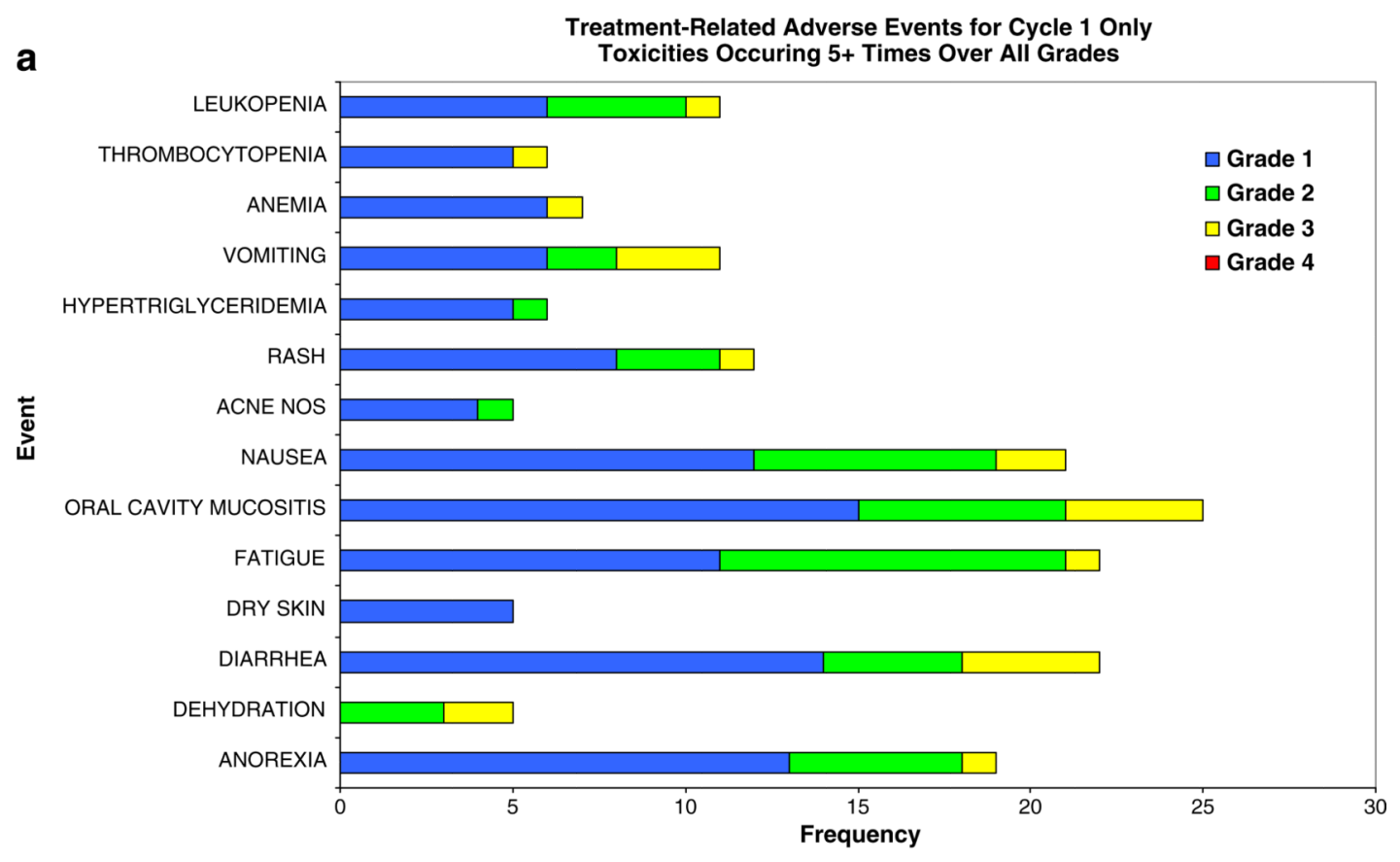

b

Treatment-Related Adverse Events Over All Cycles

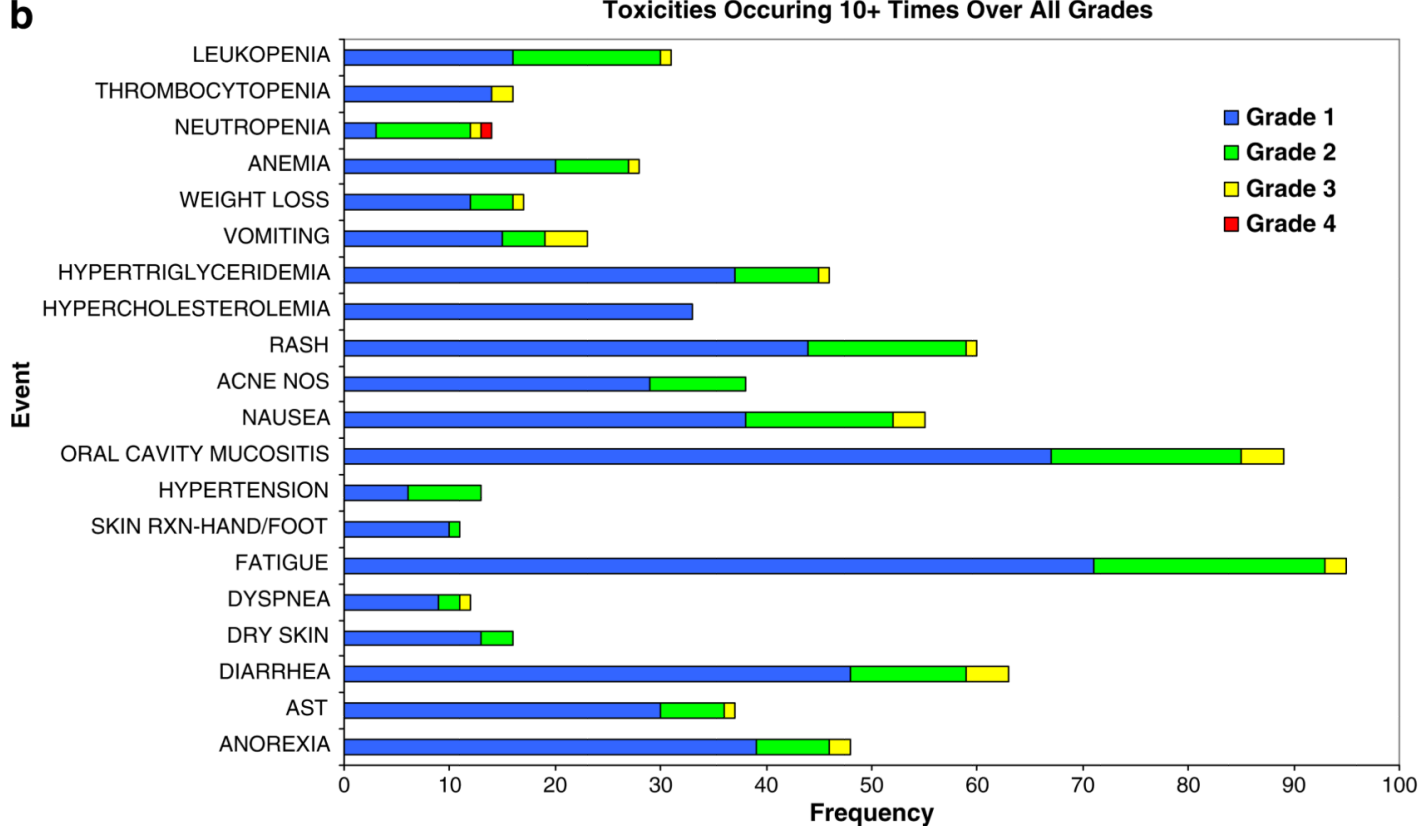

Fig. 2.

$\mathbf{a}$ and $\mathbf{b}$ Toxicities at least possibly related to treatment. Fourtyfour patients in total (11 for Cohort A1, 21 for cohort A2, 6 for both cohort B and C) were evaluable for hematological and non-hematological toxicity. All events occurring at least 5 times during Cycle 1 (a) and at least 10 times for all cycles (b) are presented 


\section{Table 1}

Dose Escalation Plan.

\begin{tabular}{|c|c|c|c|}
\hline \multirow[t]{2}{*}{ Dose Level } & \multicolumn{3}{|l|}{ Dose (mg/d) } \\
\hline & $\begin{array}{l}\text { EKB-569 } \\
\text { (days 1-28) }\end{array}$ & $\begin{array}{l}\text { temsirolimus } \\
\text { (days 1-7, 15-21) }\end{array}$ & $\begin{array}{l}\text { temsirolimus } \\
\text { (days 1-3, 15-17) }\end{array}$ \\
\hline & & Cohort A1 & \\
\hline-2 & 10 & 15 & \\
\hline-1 & 20 & 15 & \\
\hline 0 & 25 & 20 & \\
\hline \multirow[t]{2}{*}{$1^{a}$} & 35 & 25 & \\
\hline & & Cohort A2 & \\
\hline $0^{a}$ & 10 & & 30 \\
\hline 1 & 20 & & 30 \\
\hline 2 & 25 & & 30 \\
\hline $3^{b}$ & 35 & & 30 \\
\hline 4 & 45 & & 30 \\
\hline
\end{tabular}




\section{Table 3}

Dose limiting toxicities per dose level.

\begin{tabular}{llllll}
\hline & \multicolumn{2}{l}{ Cohort A1 } & & \multicolumn{2}{l}{ Cohort A2 } \\
\cline { 2 - 3 } \cline { 5 - 6 } Dose Level & No. Pts. & DLTs & & No. Pts. & DLTs \\
\hline-2 & $2(1)$ & 2 & - & - \\
-1 & 3 & 2 & - & - \\
$0^{b}$ & - & - & 6 & 1 \\
$1^{a}$ & $6(1)$ & 2 & 3 & 0 \\
2 & - & - & 3 & 0 \\
3 & - & - & 6 & 1 \\
4 & - & - & $3(1)$ & $2(1)$ \\
\hline${ }^{a}$ Starting dose for Cohort A1; & \\
$b_{\text {Starting dose for Cohort 2; () Patient replaced }}$
\end{tabular}




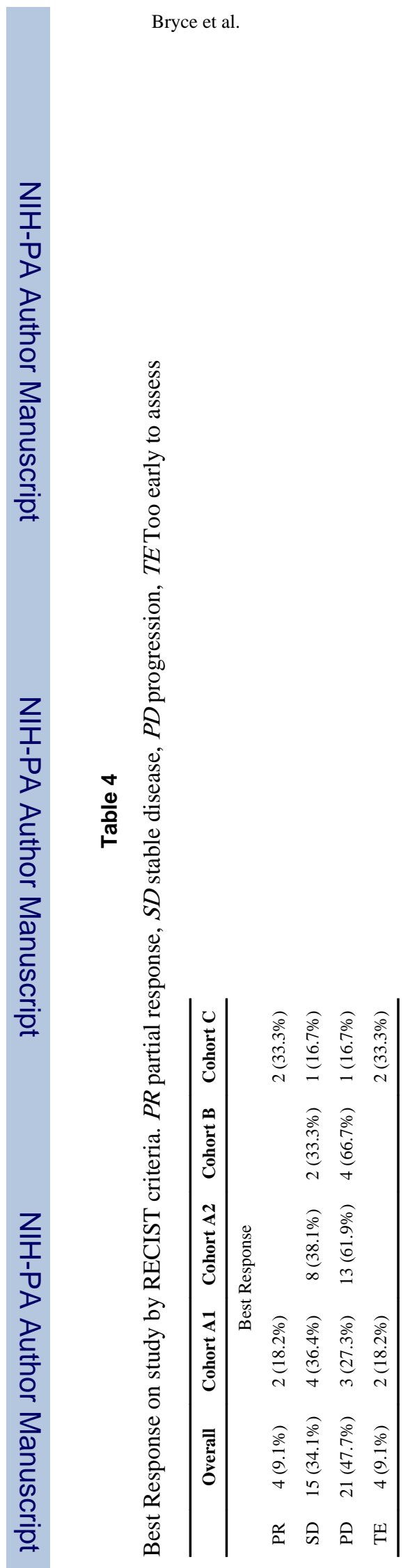

Invest New Drugs. Author manuscript; available in PMC 2013 November 04. 
